\title{
The effects of prior calcium channel blocker therapy on creatine kinase-MB levels after percutaneous coronary interventions
}

\author{
Oyku Gulmez \\ Ilyas Atar \\ Bülent Ozin \\ Mehmet Emin Korkmaz \\ Aslı Atar \\ Alp Aydinalp \\ Aylin Yildirir \\ Haldun Muderrisoglu \\ Baskent University Faculty \\ of Medicine, Department \\ of Cardiology, Ankara, Turkey
}

\begin{abstract}
Background: Use of intracoronary calcium channel blockers $(\mathrm{CCBs})$ during percutaneous coronary intervention (PCI) has been shown to have favorable effects on coronary blood flow. We aimed to investigate the effects of CCBs administrated perorally on creatine kinase-MB (CK-MB) levels in patients undergoing elective PCI.

Methods: A total of 570 patients who underwent PCI were evaluated for CK-MB elevation. Patients who were on CCB therapy when admitted to the hospital constituted the CCB group. No CCBs were given to the rest of the patients during the periprocedural period and these patients served as the control group. Blood samples for CK-MB were obtained before and at $6 \mathrm{~h}, 24 \mathrm{~h}$, and $36 \mathrm{~h}$ after the procedure.

Results: 217 patients were in the CCB group (mean age $60.2 \pm 9.3$ years, 162 males), and 353 were in the control group (mean age 60.0 10.1 years, 262 males). CK-MB levels increased above the normal values in 41 patients $(18.9 \%)$ of the CCBs group and in 97 patients $(27.5 \%)$ of the control group $(p=0.02)$. Median CK-MB levels were significantly higher in the control group for all studied hours (for all $\mathrm{p}<0.05$ ).
\end{abstract}

Conclusions: Prior oral CCB therapy may have favorable effects in preventing myocyte necrosis after elective PCI.

Keywords: calcium channel blockers, myonecrosis, percutaneous coronary interventions

\section{Introduction}

Elevation of creatine kinase-MB (CK-MB) isoenzyme due to myonecrosis after elective percutaneous coronary intervention (PCI) can be detected in 5\%-30\% of patients (Abdelmeguid and Topol 1996; Califf et al 1998; Simoons et al 1999; Tardiff et al 1999; Akkerhuis et al 2002). Factors related to the procedure such as side-branch occlusion, intimal dissection, and distal embolization have been suggested as possible causes of increased cardiac enzymes after PCI (Abdelmeguid et al 1996; Simoons et al 1999; Tardiff et al 1999). Other possible mechanisms are coronary vasospasm and no re-flow phenomenon (Demir et al 2002). Several studies have reported that elevated cardiac markers such as CK-MB and cardiac troponins (cTn) after PCI is associated with an increase in cardiac mortality and morbidity during follow-up (Abdelmeguid et al 1996; Califf et al 1998; Simoons et al 1999; Tardiff et al 1999).

Previous studies suggested intracoronary administration of calcium channel blockers (CCBs) is effective for resolving coronary spasm and no-reflow phenomenon (Michaels et al 2002; Werner et al 2002). To our knowledge there is no data about the effects of administration of oral CCBs on CK-MB levels after PCI.

The aim of this study was to investigate the effect of CCBs used perorally on CK-MB levels in patients undergoing elective PCI. 


\section{Methods}

\section{Patient population and study protocol}

The study was approved by the local Ethics Committee of Baskent University Hospital in Ankara, Turkey. All patients undergoing PCI between December 2000 and December 2005 at our institution were evaluated for eligibility for this study, and all provided written informed consent before participating. Patients who were taking a CCB at the discretion of their own primary physician on admission were noted and the drug at the same dose was continued during the hospitalization period and thereafter. No CCBs were prescribed to the patients who were not already on one. Patients presenting with acute or recent myocardial infarction (MI) within 7 days, renal insufficiency with creatinine levels higher than $1.4 \mathrm{mg} / \mathrm{dL}$, and those in whom use of a special device (laser, rotational atherectomy, brachy-therapy, etc) was planned were excluded. A total of 570 patients with elective PCI history were included in the study (mean age $60.1 \pm 9.8$ years, $74.4 \%$ males). The patients who were on a CCB on admission constituted the CCB group while the others served as controls.

There were 217 patients (mean age $60.2 \pm 9.3$ years, $74.7 \%$ males) in the CCB group and 353 patients (mean age $60.0 \pm 10.1$ years, $74.2 \%$ males) in the control group. Ninety percent of the patients in the CCB group were receiving diltiazem $180 \mathrm{mg} /$ day, whereas others were receiving amlodipine $10 \mathrm{mg} /$ day, felodipine $4 \mathrm{mg} /$ day, or verapamil $240 \mathrm{mg} /$ day.

All interventions were performed via the femoral approach. The choices of technique (percutaneous transluminal coronary angioplasty [PTCA], PTCA + stent, stent only) and adjunctive pharmacologic management were at the discretion of the operator according to the lesion characteristics. Angiographic success was defined as a residual stenosis of the treated lesion $<50 \%$ on visual estimation and -in case of stenting- desired position of the stent with Thrombolysis in Myocardial Infarction grade III flow. Commercially available drug-eluting and bare metal stents were used. All patients received aspirin $300 \mathrm{mg}$ /day, and 75-mg maintance dose of clopidogrel.

\section{Laboratory analyses}

Creatine kinase-MB isoform was measured routinely before PCI and 6, 24, and $36 \mathrm{~h}$ after PCI. Additional measurements were done for clinical indications. Levels of CK-MB were determined by an immunoinhibition assay (Roche Diagnostics, GmbH, Mannheim, Germany). The reference limit for CK-MB with this method is $0-24 \mathrm{U} / \mathrm{L}$. CK-MB levels were considered elevated if the measurement was above the normal limit in any of the follow-up measurements. The CK-MB levels were further subdivided into 1 to 3 times (24-72 U/1) and 3 to 5 times (73-120 U/l) of the normal levels.

\section{Statistical analysis}

The statistical package, SPSS version 9.0 (SSPS Inc., Chicago, IL, USA) was used for statistical analyses. Continuous variables with normal distribution were compared using the unpaired Student's t-test and were presented as the mean \pm SD. Continuous variables with abnormal distributions were compared using the Mann-Whitney $U$ test, and CK-MB results for each group were expressed as median and interquartile ranges. The CK-MB elevation within the groups were compared with the general lineer model for repeated measures test. Categorical data were reported as frequencies and percentages. Comparisons between categorical variables were performed using Fisher exact tests if any subgroup consisted of five or fewer items; otherwise, chi-square tests were used. Values for $p$ less than 0.05 were considered statistically significant.

\section{Results}

Baseline clinical and laboratory characteristics were similar between two groups (Table 1). The angiographic and procedural characteristics of the patients are listed in Table 2. No differences were observed between the groups (all $\mathrm{p}>0.05$ ). No patients died during the study period. Major adverse effects which included coronary artery spasm or dissection, the need for blood transfusion and subacute occlusion were not different between the groups (Table 2).

Baseline CK-MB levels were similar in patients in the CBB and control groups (Table 3). During in-hospital followup period for 36 hours, CK-MB levels increased above the normal values in 41 patients $(18.9 \%)$ of the CCBs group and in 97 patients $(27.5 \%)$ of the control group $(\mathrm{p}=0.02)$. The incidence of CK-MB elevation 1 to 3 times normal was $18.9 \%$ vs $26.9 \%(\mathrm{p}=0.03) ; 3$ to 5 times normal was $0.5 \%$ vs $3.1 \%(\mathrm{p}=0.03)$ in the CCB and control groups, respectively. Three patients $(0.8 \%)$ in the control group and none in the CCB group had CK-MB levels 5 times normal $(p=0.29)$. The diagnosis of postprocedural MI was based on either an increase in CK-MB 3 times the upper limit of normal, or development of pathologic $\mathrm{Q}$ waves in 2 or more contiguous electrocardiographic leads.

The median CK-MB levels were significantly higher in the control group compared with CCBs group at $6 \mathrm{~h}$, 
Table I Baseline clinical and laboratory features of CCB and control groups

\begin{tabular}{|c|c|c|c|}
\hline & $\begin{array}{l}\text { CCB group } \\
n=217\end{array}$ & $\begin{array}{l}\text { Control group } \\
n=353\end{array}$ & $P$ value \\
\hline \multicolumn{4}{|l|}{ Clinical characteristics } \\
\hline Age (year) & $60.2 \pm 9.3$ & $60.0 \pm 10.1$ & 0.79 \\
\hline Sex, male, n (\%) & $162(74.7)$ & $262(74.2)$ & 0.90 \\
\hline SAP/USAP, n (\%) & I 40 (64.5)/77 (35.5) & $232(65.7) / / 2 I(34.3)$ & 0.77 \\
\hline Diabetes mellitus, n (\%) & $50(23.0)$ & $102(28.9)$ & 0.14 \\
\hline Hypertension, n (\%) & $137(63.1)$ & $193(54.7)$ & 0.05 \\
\hline Dyslipidemia, n (\%) & $135(62.2)$ & $217(61.5)$ & 0.67 \\
\hline Smoking, n (\%) & $92(42.4)$ & $142(40.2)$ & 0.78 \\
\hline History of PCl, n (\%) & $49(22.6)$ & $53(15.0)$ & 0.05 \\
\hline History of CABG, n (\%) & $43(19.8)$ & $58(16.4)$ & 0.33 \\
\hline Mean LVEF, \% & $47 \pm 11$ & $48 \pm 12$ & 0.69 \\
\hline \multicolumn{4}{|l|}{ Drugs } \\
\hline ACE inhibitors, $n(\%)$ & $73(33.6)$ & $149(42.2)$ & 0.05 \\
\hline Statins, n (\%) & $134(6 \mid .8)$ & $228(64.6)$ & 0.49 \\
\hline Nitrates, n (\%) & $66(30.4)$ & $13 \mid(37.1)$ & 0.11 \\
\hline \multicolumn{4}{|l|}{ Laboratory Findings } \\
\hline Fasting blood sugar levels (mg/dL) & $111.9 \pm 42.2$ & $115.3 \pm 45.6$ & 0.45 \\
\hline Blood urea nitrogen levels $(\mathrm{mg} / \mathrm{dL})$ & $17.9 \pm 5.9$ & $18.3 \pm 6.5$ & 0.65 \\
\hline Creatinine (mg/dL) & $\mathrm{I} . \mathrm{I} \pm 0.8$ & $\mathrm{I} . \mathrm{I} \pm 0.6$ & 0.99 \\
\hline LDL cholesterol (mg/dL) & $112.3 \pm 39.3$ & $111.3 \pm 38.6$ & 0.79 \\
\hline Triglyceride (mg/dL) & $154.5 \pm 76.6$ & $164.5 \pm 94.5$ & 0.28 \\
\hline Hemoglobin (g/dL) & $14.1 \pm 1.6$ & $13.7 \pm 1.7$ & 0.06 \\
\hline
\end{tabular}

Abbreviations: $C C B$, calcium channel blocker; $P C l$, percutaneous coronary interventions; $C A B G$, coronary artery bypass graft surgery; LVEF, left ventricular ejection fraction; SAP, stable angina pectoris; USAP, unstable angina pectoris; ACE, angiotensin-converting enzyme; LDL, low-density lipoprotein.

Table 2 Details of $\mathrm{PCl}$ procedures between groups

\begin{tabular}{|c|c|c|c|}
\hline & $\begin{array}{l}\text { CCB group } \\
n=217\end{array}$ & $\begin{array}{l}\text { Control group } \\
n=353\end{array}$ & $P$ value \\
\hline \multicolumn{4}{|l|}{ Dilated coronary artery } \\
\hline Left anterior descending, n (\%) & $89(41.0)$ & $174(49.3)$ & 0.05 \\
\hline Left circumflex, n (\%) & $79(36.4)$ & II 8 (33.4) & 0.46 \\
\hline Right coronary artery, n (\%) & $74(34.1)$ & $100(28.3)$ & 0.15 \\
\hline Graft lesion, n (\%) & $13.0(6.0)$ & $13(3.7)$ & 0.19 \\
\hline Multi-vessel PCl, n (\%) & $4 \mid(18.9)$ & $60(17.0)$ & 0.56 \\
\hline Drug-eluting stent, n (\%) & $5(2.3)$ & II (3.I) & 0.79 \\
\hline Stent used per procedure, $\mathrm{n}(\%)$ & $1.3 \pm 0.4$ & $1.3 \pm 0.4$ & 0.77 \\
\hline Mean stent length $(\mathrm{mm})$ & $13.3 \pm 6.5$ & $13.3 \pm 6.7$ & 0.92 \\
\hline Mean stent diameter $(\mathrm{mm})$ & $2.9 \pm 0.4$ & $3.0 \pm 0.4$ & 0.16 \\
\hline Total inflation time, s & $124.2 \pm 85.7$ & $114.8 \pm 83.3$ & 0.23 \\
\hline Max inflation pressure, atm & $11.8 \pm 5.4$ & $11.8 \pm 4.1$ & 0.99 \\
\hline Spasm, n (\%) & $6(2.8)$ & $6(1.7)$ & 0.39 \\
\hline Dissections, n (\%) & $3(1.4)$ & $6(1.7)$ & 1.00 \\
\hline Blood transfusion, n (\%) & $2(0.9)$ & $3(0.8)$ & 1.00 \\
\hline Subacute occlusion, n (\%) & $5(2.3)$ & $7(2.9)$ & 0.77 \\
\hline
\end{tabular}

Abbreviations: $\mathrm{CCB}$, calcium channel blockers; $\mathrm{CK}-\mathrm{MB}$, creatine kinase-MB; $\mathrm{PCl}$, percutaneous coronary interventions. 
Table 3 Median (interquartile range) CK-MB levels of the groups during follow-up

\begin{tabular}{llll}
\hline & CCB group $\mathbf{n}=\mathbf{2} 1 \mathbf{7}$ & Control group $\mathbf{n}=\mathbf{3 5 3}$ & $\mathbf{P}$ value \\
\hline Baseline CK-MB, U/L & $11.0(7.0-16.0)$ & $12.0(8.0-17.0)$ & 0.13 \\
After PCI, 6th hours CK-MB, U/L & $14.0(8.2-21.0)$ & $15(10.2-21.0)$ & 0.03 \\
After PCI, 24th hours CK-MB, U/L & $13.0(9.0-19.7)$ & $16.0(11.0-22.0)$ & 0.001 \\
After PCI, 36th hours CK-MB, U/L & $13.0(8.0-20.0)$ & $15.0(10.0-24.0)$ & 0.000 \\
\hline
\end{tabular}

Abbreviations: $\mathrm{CCB}$, calcium channel blockers; CK-MB, creatine kinase-MB; $\mathrm{PCl}$, percutaneous coronary interventions.

$24 \mathrm{~h}, 36 \mathrm{~h}$ after PCI (Table 3). The elevations of CK-MB levels were statistically significant within the groups (both $\mathrm{p}<0.001$ ) (Figure 1).

\section{Discussion}

Both previous retrospective studies and prospective randomized trials have shown that development of new treatment strategies like intracoronary nitrate infusion, oral statins, glycoprotein IIb/IIIa inhibitors and adenosine reduce ischemic complications, death, nonfatal myocardial infarction, and release of CK-MB after coronary interventions when compared with placebo (EPISTENT 1998; Kurz et al 2000; Desmet et al 2002; Hermann et al 2002; Aronow et al 2002a, 2002b; Wang et al 2003; Pasceri et al 2004). Moreover, recently published trials demonstrated beneficial effects of beta blockers on CK-MB levels in patients with PCI as well (Roberts et al 1991; Sharma et al 2000; Ellis et al 2001; Wang et al 2003; Sato et al 2004).
Several studies have shown that intracoronary administration of CCBs reduces procedural myonecrosis in patients undergoing elective or urgent PCI. Demir and colleagues (2002) and Werner and colleagues (2002) have reported that intracoronary verapamil has favourable effects on coronary vasospasm and no-reflow phenomenon in patients with primary PTCA for acute MI. In VAPOR (VAsodilator Prevention On no-Reflow) trial intragraft verapamil was given pre-PCI to prevent no-reflow and there was a trend toward improved myocardial perfusion as assessed using the TIMI myocardial perfusion grade (TMPG) (Michaels et al 2002). In the VESPA (VErapamil Slow-Release for Prevention of Cardiovascular Events After Angioplasty) trial, $240 \mathrm{mg} / \mathrm{d}$ verapamil administered for six months after PCI reduced the incidence of need for repeat target vessel revascularization (Bestehorn et al 2004). A new recent meta-analysis of the two largest trials, Nisoldipine in Coronary artery Disease in Leuven (NICOLE) and Coronary

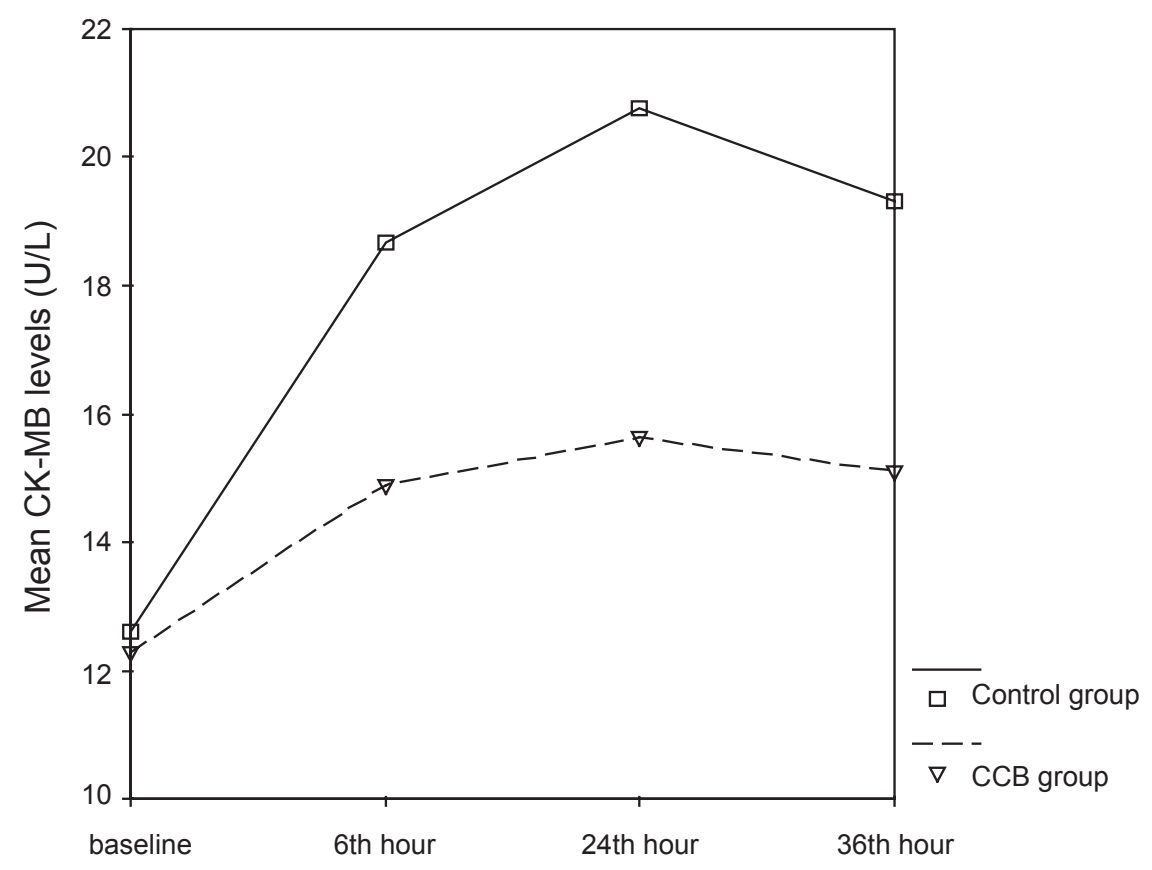

Figure I Mean CK-MB levels of the groups during follow-up.

Abbreviations: CCB, calcium channel blockers; CK-MB, creatine kinase-MB. 
Angioplasty Amlodipine in Restenosis Study (CAPARES), found that CCBs improved long term clinical outcome and reduced the need for target vessel revascularization when compared with placebo (Dens et al 2003). It was concluded that this might be due to the antiproliferative properties of CCBs which were demonstrated in in vitro experiments (Yang et al 1993; Voisard et al 1997). Moreover, the recently published trial by Matthews and colleagues (2005) demonstrated that using intracoronary $\mathrm{CCB}$ at the time of PCI result in lower postprocedural creatine phosphokinase (CPK) values and smaller areas under the CPK curve.

The aim of our study was to evaluate the relationship between systemic administration of CCBs and the elevation of CK-MB suggestive of myonecrosis. The results indicate that in elective PCI, per procedural CCBs usage may be associated with reduced CK-MB release. The cardioprotective effects of CCBs' observed in our study can be explained by several mechanisms.

Klein and colleagues (1989) have found that the development of infarcts were significantly delayed and the mean infarct sizes were smaller with intracoronary infusion of diltiazem, verapamil or nifedipine indicating that CCBs increase the ischemic tolerance significantly by their effects on calcium homeostasis in the setting of acute ischemia during baloon inflations at PCI.

The CCBs may also protect the patients against fatal or nonfatal infarction via their platelet-inhibiting effects. Folts (1997) have reported that IV amlodipine administration was found to be protective against exacarbation of coronary thrombosis by epinephrine in dog model of experimental coronary artery thrombosis.

CCBs' may also improve nitric oxide (NO) release and improve endothelial functions (Taddei et al 2001). The ENCORE Investigators (Evaluation of Nifedipine and Cerivastatin on Recovery of Coronary Endothelial function) have reported that 30 to $60 \mathrm{mg} / \mathrm{d}$ nifedipine treatment over a 6 month period improved coronary endothelial function in the most constricted segment. Mechanisms that could be targeted by CCBs' include antioxidative properties and effects on endothelial nitric oxide synthase (eNOS) expression and activity (ENCORE 2003). The present study was not designed to evaluate the mechanism by which CCBs might prevent myonecrosis after PCI and we do not know the factors affecting our results.

\section{Study limitations}

There are several limitations of this study. This study is a nonrandomized study with lack of clinical follow-up.
The patient numbers in the present study are small and lack the ability of a prospective randomized trial to minimize differences between the groups. The groups were formed before the study and the patients who were receiving CCBs at the discretion of their physician constituted the drug group, so the patients used different types and doses of CCBs. We did not collect any data on myocardial perfusion by angiography (TIMI frame count, myocardial perfusion blush scores), dynamic ST-segment changes to identify a relation with no-reflow at any time during mechanical perfusion. The number of patients with CK-MB elevations in both groups was small, and all patients at both groups had a very low incidence of MI after PCI.

\section{Conclusion}

Despite these limitations, the study points out that systemic administration of CCBs may be associated with reduced CK-MB release after elective PCIs. Long-term prospective randomized trials are required to confirm the effects of $\mathrm{CCBs}$ on myocyte necrosis in patients undergoing elective PCI.

\section{Disclosure}

None of the authors have associations that might pose a conflict of interest. No financial support from any organization was used.

\section{References}

Abdelmeguid AE, Topol EJ, Whitlow PL, et al. 1996. Significance of mild transient release of creatine kinase-MB fraction after percutaneous coronary interventions. Circulation, 94:1528-36.

Abdelmeguid AE, Topol EJ. 1996. The myth of the myocardial 'infarctlet' during percutaneous coronary revascularization procedures. Circulation, 94:3369-75.

Akkerhuis KM, Alexander JH, Tardiff BE, et al. 2002. Minor myocardial damage and prognosis. Circulation, 105:554-6.

Aronow HD, McRae T, Quinn MJ. 2002b. Patients on lipid-lowering therapy at the time of myocardial infarction have smaller infarcts: further evidence to suggest a salutary effect in acute coronary syndrome [abstract]. J Am Coll Cardiol, 39:318A.

Aronow HD, Quinn MJ, Gurm HS. 2002a. Myocardial necrosis is halved in patients undergoing elective percutaneous coronary intervention who are pretreated with lipid-lowering therapy [abstract]. J Am Coll Cardiol, 39:32A.

Bestehorn HP, Neumann FJ, Büttner HJ, et al. 2004. Evaluation of the oral verapamil on clinical outcome and angiographic restenosis after percutaneous coronary intervention. The randomized, double-blind, placebo-controlled, multicenter verapamil slow-release for prevention of cardiovascular events after angioplasty (VESPA) trial. $J$ Am Coll Cardiol, 43:2160-5.

Califf RM, Abdelmeguid AE, Kuntz RE, et al. 1998. Myonecrosis after revascularization procedures. J Am Coll Cardiol, 31:241-51.

Demir I, Yılmaz H, Ermiş C, et al. 2002. Treatment of no re-flow phenomenon with verapamil after primary stent deployment during myocardial infarction. Jpn Heart J, 43:573-80.

Dens J, Desmet W, Piessens J. 2003. An updated meta-analysis of calcium-channel blockers in the prevention of restenosis after coronary angioplasty. Am Heart J, 145:404-8. 
Desmet WJ, Dens J, Coussement P, et al. 2002. Does adenosine prevent myocardial micronecrosis following percutaneous coronary intervention? The ADELINE pilot trial. ADEnosine Limit myocardial Necrosis. Heart, 88:293-5.

Ellis S, Sorin JB, Lincoff AM, et al. 2001. Beta-blockers before percutaneous coronary intervention do not attenuate postprocedural creatine kinase isoenzyme rise. Circulation, 104:2685-8.

[ENCORE] The ENCORE Investigators. 2003. Effect of nifedipine and cerivastatin on coronary endothelial function in patients with coronary artery disease: the ENCORE I Study (Evaluation of Nifedipine and Cerivastatin in Recovery of coronary Endothelial function). Circulation, 107:422-8.

[EPISTENT] The EPISTENT Investigators. 1998. Randomized placebocontrolled and balloon-angioplasty-controlled trial to assess safety of coronary stenting with use of platelet glycoprotein-IIb/IIIa blockade. Lancet, 352:87-92.

Folts JD. 1997. Inhibition of platelet activity in vivo by amlodipine alone and combined with aspirin. Int J Cardiol, 62: S111-7.

Herrmann J, Lerman A, Baumgart D, et al. 2002. Preprocedural statin medication reduces the extent of per procedural non-Q-wave myocardial infarction. Circulation, 106:2180-3.

Klein HH, Pich S, Lindert S, et al. 1989. Comparative study on the enchanment of ischemic tolerance by intracoronary pretreatment with three calcium antagonists in pig hearts. Cardiovasc Drugs Ther, 2:815-21.

Kurz DJ, Naegeli B, Bertel O. 2000. A double-blind, randomized study of the effect of immediate intravenous nitroglycerin on the incidence of postprocedural chest pain and minor myocardial necrosis after elective coronary stenting. Am Heart J, 139:35-43.

Matthews MA, Kunselman SJ, Gascho JA, et al. 2005. Differential release of cardiac enzymes after percutaneous coronary intervention. Catheter Cardiovasc Interv, 65:19-24.

Michaels AD, Appleby M, Otten MH, et al. 2002. Pretreatment with intragraft verapamil prior to PCI of saphenous vein graft lesions: results of the randomised controlled vasodilator prevention on no-reflow (VAPOR) trial. J Invasive Cardiol, 14:299-302.

Pasceri V, Patti G, Nusca A, et al; ARMYDA Investigators. 2004. Randomized trial of atorvastatin for reduction of myocardial damage during coronary intervention: results from the ARMYDA (Atorvastatin for Reduction of MYocardial Damage during Angioplasty) study. Circulation, 110:674-8.
Roberts R, Rogers WJ, Mueller HS, et al. 1991. Immediate versus deferred B-blockage following thrombolytic therapy in patients with acute myocardial infarction: results of the thrombolysis in myocardial infarction (TIMI) II-B study. Circulation, 83:422-37.

Sato M, Harding SE, Poole-Wilson PA. 2004. B-blockers, myocardial ischemia and collateral circulation. Eur Heart J, 25:537-9.

Sharma SK, Kini A, Marmur JD, et al. 2000. Cardioprotective effect of prior B-blocker therapy in reducing creatine- kinase-MB elevation after coronary intervention: benefit is extended to improvement in intermediate-term survival. Circulation, 102:166-72.

Simoons ML, van den Brand M, Lincoff M, et al. 1999. Minimal myocardial damage during coronary intervention is associated with impaired outcome. Eur Heart J, 20:1112-9.

Taddei S, Virdis A, Ghiadoni L, et al. 2001. Restoration of nitric oxide availability after calcium antagonist treatment in essential hypertension. Hypertension, 37:943-8.

Tardiff BE, Califf RM, Tcheng JE, et al. 1999. Clinical outcomes after detection of elevated cardiac enyzmes in patients undergoing percutaneous intervention. IMPACT II Investigators. Integrilin (eptifibatide) to Minimize Platelet Aggregation and Coronary Thrombosis-II. J Am Coll Cardiol, 33:88-96.

Voisard R, Koschnick S, Baur R, et al. 1997. High-dose diltiazem prevents migration and proliferation of vascular smooth muscle cells in various in-vitro models of human coronary restenosis. Coron Artery Dis, 8:189-201.

Wang FW, Osman A, Otero J, et al. 2003. Distal myocardial protection during percutaneous coronary intervention with an intracoronary betablocker. Circulation, 107:2914-9.

Werner GS, Lang K, Kuehnert H, et al. 2002. Intracoronary verapamil for reversal of no-reflow during coronary angioplasty for acute myocardial infarction. Cathet Cardiovasc Interv, 57:444-51.

Yang Z, Noll G, Luscher TF. 1993. Calcium channel antagonists differently inhibit proliferation of human coronary smooth muscle cells in response to pulsatile stretch and platelet derived growth factor. Circulation, 88:832-6. 